\title{
Temperature and Precipitation Skill as a Function of the Day of the Week
}

\author{
Lance F. Bosart
}

Department of Atmospheric Science, State University

of New York at Albany, Albany, N.Y. 12222

I have always wondered whether my daily weather forecasts made on Monday would exhibit somewhat less skill than those made later in the week, when presumably I would be enjoying the benefit of full day-to-day weather map continuity. This question is addressed in this note. I have examined the daily consensus probability temperature and precipitation forecasts made at the State University of New York at Albany for the period September 1969-December 1976. A total of 1023 daily forecasts were made during this period. Complete details on the game format can be found in Bosart (1975). Briefly, each day a forecast of the probability of the minimum temperature going below normal at Albany was made for $24 \mathrm{~h}$ periods out to four days in advance. A similar procedure was employed for probability forecasts of the chance of measurable precipitation. The Brier (1950) scoring rule was used. A unique feature of the game was the construction of a daily consensus forecast. Approximately 10-20 individual forecasts made up the daily consensus forecast. Forecast skill was measured by the percent improvement over the control forecast, which was a persistence climatology based upon 30 years of prior records at Albany.

Table 1 gives the breakdown of the average daily Brier score for consensus temperature and precipitation forecasts. The persistence climatology score is also included. No obvious difference exists among different days of the week. The average daily consensus temperature and precipitation score was 71.2 and 77.7. This yields chi-square values of 0.43 and 0.08 , respectively, versus a $5 \%$ significance level chi-square of 9.49 for four degrees of freedom.

TABLE 1. Daily average consensus and control Brier score.

\begin{tabular}{|c|c|c|c|c|c|}
\hline & \multirow{2}{*}{$\begin{array}{c}\text { Number } \\
\text { of } \\
\text { fore- } \\
\text { casts }\end{array}$} & \multicolumn{2}{|c|}{ Temperature } & \multicolumn{2}{|c|}{ Precipitation } \\
\hline & & $\begin{array}{l}\text { Con- } \\
\text { sensus }\end{array}$ & $\begin{array}{c}\text { Con- } \\
\text { trol }\end{array}$ & $\begin{array}{l}\text { Con- } \\
\text { sensus }\end{array}$ & $\begin{array}{c}\text { Con- } \\
\text { trol }\end{array}$ \\
\hline Monday & 198 & 68.7 & 98.4 & 76.1 & 93.2 \\
\hline Tuesday & 211 & 68.1 & 97.0 & 78.8 & 95.3 \\
\hline Wednesday & 208 & 71.3 & 93.8 & 78.8 & 96.2 \\
\hline Thursday & 203 & 74.0 & 97.5 & 77.7 & 98.2 \\
\hline Friday & 203 & 73.8 & 97.1 & 77.1 & 97.7 \\
\hline
\end{tabular}

0003-0007/79/121428-01\$04.25

(C) 1979 American Meteorological Society
TABLE 2. Daily consensus skill relative to the climatological control defined by percent improvement over the control forecast.

\begin{tabular}{lcc}
\hline \hline & Temperature & Precipitation \\
\hline Monday & 30.2 & 18.3 \\
Tuesday & 29.8 & 17.3 \\
Wednesday & 24.0 & 18.0 \\
Thursday & 24.1 & 20.8 \\
Friday & 23.9 & 21.0 \\
\hline
\end{tabular}

Table 2 gives the daily percentage improvement of consensus over the climatological control: [ (control - consensus)/control $] \times 100 \%$. Note the tendency for more skillful temperature forecasts on Monday and Tuesday, whereas precipitation forecast skills peak on Thursday and Friday. The results are far from statistically significant, however. The average daily consensus temperature and precipitation skill is $26.4 \%$ and $19.1 \%$, respectively. This yields chi-square values of 1.65 and 0.60 , which are well below the previous $95 \%$ significance threshold.

My preconception was that scores would be worst on Monday and then get better. For temperature just the opposite is true, with the Friday consensus skill 6\% less than Monday. Precipitation skills are apparently less sensitive but follow the preconceived idea. Could it be that the temperature results represent increasing daily fatigue such that by Friday you could not care less about temperature as you begin to put forecast adrenalin into the question of weekend rain? Come Monday morning again you are refreshed by the weekend and ready to deal with temperature. Idle speculation? Perhaps, but this is what makes life interesting.

Acknowledgment. I thank Mr. David Palmiero for his valuable data tabulation for this study.

\section{References}

Bosart, L. F., 1975: SUNYA experimental results in forecasting daily temperature and precipitation. Mon. Wea. Rev., 103, 1013-1020.

Brier, G. W., 1950: Verification of forecasts expressed in terms of probability. Mon. Wea. Rev., 78, 1-3. 